\title{
Os limites da política de cotas para as disputas eleitorais: A sub- representação feminina a partir do estudo de caso da Câmara Municipal da cidade de Uberlândia
}

\section{The limits of the quota policy for electoral disputes: The female sub- representation from the case study of the city of Uberlândia city hall}

\author{
Alecilda Aparecida Alves Oliveira ${ }^{1}$
}

\begin{abstract}
Resumo
No Brasil, a presença de mulheres é bastante expressiva no âmbito das organizações e associações que compõem a sociedade, mas, ao se analisar a esfera político institucional - entendendo esta composta pelos partidos políticos, parlamentos e governos - esses números caem drasticamente. Com o intuito de influir diretamente na diferença entre mulheres e homens no interior desses espaços públicos, implantou-se no Brasil, em setembro de 1995, a Lei n. 9.100 de cotas por sexo para a disputa legislativa. Essa lei determina a obrigatoriedade de que cada partido ou coligação reserve o mínimo de trinta por cento e o máximo de setenta por cento de vagas para candidaturas de cada sexo. Trouxe como objetivo o aumento no número de candidaturas femininas e, consequentemente, a elegibilidade de mulheres. Neste texto, realiza-se um mapeamento do seu desempenho no que se refere à participação feminina na Câmara Municipal da cidade de Uberlândia, ponderando acerca das candidaturas e da elegibilidade das mulheres.
\end{abstract}

Palavras chave: gênero; participação política; política de cotas; sub-representação feminina.

\begin{abstract}
In Brazil, the presence of women is quite expressive in the context of the organizations and associations that make up society, however, when analyzing the institutional political sphere - considering it is composed by political parties, parliaments, and governments - these numbers drop dramatically. In order to directly influence the difference between women and men within these public spaces, the Law no. 9,100, regarding sex quotas for legislative dispute, was implanted in September 1995 in Brazil. This law mandates that each party or coalition must reserve a minimum of thirty percent and a maximum of seventy percent of seats for candidates of each sex. Its objective was to increase the number of female candidates, and consequently, the
\end{abstract}

\footnotetext{
1 Atualmente é professora do Curso de Direito da Universidade do Estado de Minas Gerais (UEMG), Unidade Ituiutaba, da Faculdade Mais (FACMAIS) e da Educação Básica do Estado de Minas Gerais.
} 
Os limites da política de cotas para as disputas eleitorais: A sub-representação feminina a partir do estudo de caso da Câmara Municipal da cidade de Uberlândia Alecilda Aparecida Alves Oliveira

eligibility of women. In this text, a mapping of their performance with regard to women's participation in the City Council of the city of Uberlândia is made, considering the candidacies and the eligibility of women. Keywords: gender; political participation; quota policy; female underrepresentation.

\section{Introdução}

Este texto resulta de uma pesquisa acerca da sub-representação das mulheres na Câmara Municipal da cidade de Uberlândia, Minas Gerais, realizada em parte como Iniciação Científica e, posteriormente, dando continuidade ao trabalho monográfico que serve como requisito para a conclusão acadêmica. Neste caso, na área de Ciências Sociais. Torna-se importante esse destaque, uma vez que desde a sua escrita foram possíveis amadurecimentos teóricos e também a busca por um aprimoramento da análise até então realizada. Este, com toda a certeza, é o exercício constante daqueles(as) que se dedicam ao "fazer científico".

Para o tratamento do processo de ampliação da cidadania e de correção de assimetrias, a valorização das "diferenças", abarcando componentes como as relações de gênero, raça/etnia, geracional e socioeconômicas, ganhou centralidade para a compreensão sobre um tipo particular de organização do Poder, do Governo e do Estado. É nesse contexto que a reflexão sobre as mulheres na atuação política se faz presente e necessária.

No Brasil, as mulheres representam 52\% (cinquenta e dois porcento) do eleitorado ${ }^{2}$, mas ao se analisar o espaço político-institucional - entendendo este pelos partidos políticos, parlamentos e governos - esses números caem drasticamente. Dados do Tribunal Superior Eleitoral (TSE) referentes ao período em que a pesquisa foi realizada, entre 2011 e 2012, revelavam que o Brasil ocupa um dos piores lugares no ranking mundial da participação feminina na política.

$\mathrm{Na}$ época, das 513 (quinhentas e treze) vagas disponibilizadas pela Câmara dos Deputados, apenas 45 (quarenta e cinco) haviam sido preenchidas por mulheres, o equivalente a 8,7\% do total de parlamentares. No Senado Federal, havia, até então, 11 (onze) senadoras e 70 (setenta) senadores, ou seja, apenas $13,5 \%$ do total de parlamentares da casa eram mulheres (RANGEL, 2010).

Nas últimas eleições para o Congresso Nacional, em 2018, tivemos uma mudança neste cenário. De acordo com a matéria ${ }^{3}$ disponibilizada no sítio eletrônico do TSE, o número de

2 Disponível em: http://www.tse.jus.br/imprensa/noticias-tse/2018/Marco/mulheres-representam-52-doeleitorado-brasileiro

${ }^{3}$ Disponível em: http://www.tse.jus.br/imprensa/noticias-tse/2019/Marco/numero-de-mulheres-eleitas-em-2018cresce-52-6-em-relacao-a-2014 
Os limites da política de cotas para as disputas eleitorais: A sub-representação feminina a partir do estudo de caso da Câmara Municipal da cidade de Uberlândia Alecilda Aparecida Alves Oliveira

mulheres eleitas naquele pleito para a Câmara dos Deputados aumentou em 51\% em relação ao anterior, em 2014. Foram eleitas 77 (setenta e sete) mulheres para a casa. No ano de 2014 contávamos apenas com 51 (cinquenta e uma) mulheres parlamentares. Para o Senado não tivemos mudanças, o número de eleitas se manteve o mesmo que o alcançado no pleito anterior, em 2010. Foram 7 (sete) mulheres eleitas, o que representa 13\% dos parlamentares da casa. Esses dados refletem mais uma das formas de opressão que marcam a vida das mulheres.

Com o intuito de influir diretamente na diferença entre mulheres e homens no interior desses espaços públicos - de discussão, decisão e intervenção política -, implantou-se no Brasil, em setembro de 1997, a lei de cotas por sexo para a disputa legislativa. Neste texto será realizada a análise desta política de cotas por sexo para cargos eletivos do legislativo estadual/distrital, federal e municipal. Tal análise será feita a partir do estudo de caso do Legislativo de Uberlândia, ponderando acerca da participação feminina no âmbito da Câmara Municipal da cidade de Uberlândia a partir das candidaturas e da elegibilidade das parlamentares.

\section{Entendendo a política de cotas}

Os dados do Tribunal Superior Eleitoral (TSE) mencionados no início da exposição dizem muito a respeito dos caminhos percorridos por essa medida. Concluídos onze processos eleitorais - sendo que 1998, 2002, 2006, 2010, 2014 e 2018 se referem, respectivamente, às disputas estaduais/distritais e federais, e 2000, 2004, 2008, 2012 e 2016 às disputas municipais -, ainda é possível conjecturar que os números referentes à presença de mulheres no legislativo estão aquém daqueles esperados com a implementação da lei, demonstrando que ainda persiste uma subrepresentação feminina no espaço da política institucional.

A política de cotas corresponde a uma medida, resultante de ações empreendidas por setores dos movimentos sociais e representantes da política nacional. Por meio dela determinou-se a obrigatoriedade de que cada partido - e até as últimas eleições as coligações, agora extintas para a disputa proporcional - reserve o mínimo de 30\% (trinta por cento) e o máximo de $70 \%$ (setenta por cento) de vagas para candidaturas de cada sexo. Ou seja, a partir dela estabeleceu-se a obrigatoriedade de uma quantidade mínima de mulheres nas chapas concorrentes à disputa eleitoral. O objetivo desta medida é aumentar o número de candidaturas femininas e, consequentemente, a elegibilidade de mulheres (GROSSI \& MIGUEL, 2001; MIGUEL, 2000).

De acordo com Miguel (2000), a política de cotas por sexo para a disputa legislativa se insere em um contexto de adoção de ações afirmativas ou discriminações positivas no sentido de afirmar, recuperar e redistribuir direitos. Estes dispositivos vêm sendo aplicados para, na prática, 
Os limites da política de cotas para as disputas eleitorais: A sub-representação feminina a partir do estudo de caso da Câmara Municipal da cidade de Uberlândia Alecilda Aparecida Alves Oliveira

equilibrar relações de gênero, raça/etnia ou geração em diferentes esferas da vida social. No que se refere a situação das mulheres nos espaços de tomada de decisão, temos ainda a perspectiva de que tais ações podem contribuir para o empoderamento feminino.

Para autores e autoras que trabalham com esta categoria, o empoderamento se fundamenta em uma noção de poder como elemento a ser partilhado tendo por base relações sociais mais democráticas. Deste modo, o ato de “empoderar-se” significa a aquisição de controle de suas vidas, obter a habilidade de fazer coisas e tomar as decisões que julgar mais acertadas (MARIANO \& SOUSA, 2019).

O empoderamento feminino requer a promoção de mecanismos institucionais, econômicos, políticos e sociais que atribuam às mulheres maior capacidade de defender seus interesses e comandar suas próprias vidas. A forma mais universalista possível para implantar tais mecanismos é por meio de políticas públicas, com a incorporação da perspectiva de gênero (MARIANO \& SOUSA, 2019). Faz-se importante que essa incorporação de uma perspectiva de gênero não venha descolada de ações que visem alterar a lógica das desigualdades, contemplando também outras dimensões.

O conceito de empoderamento, assim como muitos outros, não é consensual, mas tem há algum tempo feito parte das discussões acerca da ocupação de espaços anteriormente exclusivos aos homens. Essa concepção implica que o sujeito se converta em agente ativo, portando, de certo modo, um caráter emancipador. Por outro lado, pode-se explorar a concepção emancipacionista das mulheres já elaborada anteriormente e com trajetória teórica e política, como uma perspectiva para vencer as opressões a que as mulheres são submetidas. O presente texto não terá condições de fazê-lo, mas o aponta como um debate frutífero.

\section{Dicotomia público/privado nas relações de gênero}

Houve um tempo em que as categorias mulher e política eram tratadas como excludentes, sob a alegação de que existiam espaços e papéis adequados aos homens e às mulheres. É importante, ainda, mencionar que já tivemos momentos da história de nossa civilização em que às mulheres não eram conferidas a condição de cidadãs. ${ }^{4}$

Estavam às mulheres destinados os espaços privados, não políticos - aqueles referentes à casa, aos cuidados com os filhos e com a família - enquanto aos homens era possibilitado o acesso aos espaços públicos, de debates e tomadas de decisão. É importante ressaltar que não se nega que

\footnotetext{
4 Temos como exemplo as cidade-estado gregas, na Antiguidade, em que condição era colocada às mulheres, mas este é um fato recorrente em vários outros períodos.
} 
Os limites da política de cotas para as disputas eleitorais: A sub-representação feminina a partir do estudo de caso da Câmara Municipal da cidade de Uberlândia Alecilda Aparecida Alves Oliveira

todos estes espaços, sejam considerados públicos ou privados, são espaços de disputa de poder.

Conforme aponta com Flávia Biroli, "essa dualidade corresponde a uma compreensão restrita de política, que, em nome da universalidade na esfera pública, define uma série de tópicos e experiências como privados e, como tal, não políticos" (BIROLI, 2014, p. 31). Esta é uma estratégia de isolamento das relações de poder na vida cotidiana, não reconhecendo "o caráter político ou conflitivo das relações de trabalho e das relações familiares” (BIROLI, 2014, p. 31) e a necessidade de levar seus convites ao debate público.

Desta dicotomia, no que concerne às relações de gênero, as mulheres historicamente foram forjadas como "naturalmente" inadequadas à esfera pública e, portanto, incapazes de exercer domínio sobre suas vidas, tornando-se dependentes dos homens e subordinadas à família. Por muito tempo, também, as mulheres tiveram como saída compulsórias para suas vidas o casamento e a reprodução. Enquanto aos homens permitia-se a ocupação das esferas da vida econômica e política e a legislação sobre a vida de outros homens e mulheres (OKIN, 2008).

No que se refere à conquista de direitos, temos também historicamente a condição de desvantagem das mulheres em relação aos homens, concretizando um distanciamento entre a cidadania formal e a cidadania real. Pertencentes à concepção liberal moderna, tanto os direitos políticos como os direitos civis foram defendidos como direitos de um sujeito moderno abstrato. E desta abstração, mesmo que em busca de uma universalidade, esse indivíduo traduziu-se no perfil de homens, brancos, adultos e livres.

Com isso, buscou-se por muito tempo "a preservação da esfera privada em relação à intervenção do Estado" e, com isso, "a preservação das relações de autoridade que limitaram a autonomia das mulheres” (BIROLI, 2014, p. 32). O contratualista liberal, John Locke, por exemplo, definia o poder político distinguindo-o das relações que operam dentro dos limites da casa. Com isso quer se estabelecer, por exemplo, que o Estado está isento ao que acontece na vida privada de seus cidadãos.

A distinção liberal entre os espaços público e privado projeta a sociedade através de uma perspectiva baseada em diferentes papéis para homens e mulheres. Uma distinção como essa não cabe em uma teoria política que se pretenda inclusiva, representativa de homens e mulheres.

Em consequência disso, aspectos relevantes atribuídos a esfera privada demoraram a receber sua politização e tratamentos devidos. Temos exemplos como a tipificação da violência doméstica e do estupro no casamento, os abusos perpetrados em nome da privacidade, proteção e autonomia da família, a distribuição desigual de responsabilidades no cuidado com as crianças e atividades domésticas, a dependência e subordinação econômica das mulheres em relação aos 
Os limites da política de cotas para as disputas eleitorais: A sub-representação feminina a partir do estudo de caso da Câmara Municipal da cidade de Uberlândia Alecilda Aparecida Alves Oliveira

homens, entre outros (BIROLI, 2014).

A "politização do privado", daquilo que é definido como pessoal, desafia ainda concepções de mundo que insistem em assumir que a criação dos filhos e os cuidados com o ambiente doméstico são tarefas exclusivamente femininas. Estes são aspectos objetivos da realidade social, inclusive, que fazem com que mulheres desistam da participação em espaços de tomada de decisão e não tenham as mesmas chances que homens nessa arena de disputa.

Com isto, evidencia-se que a reprodução social e, com ela a divisão do trabalho doméstico e a conservação da mulher frente à criação dos(as) filhos(as), precisa ser pautada pela teoria política a fim de promover análises que possam modificar a realidade social.

\section{Balanço da participação feminina nas eleições para o legislativo de Uberlândia}

Partindo da conjectura de que a política institucional, ainda no tempo presente, tende a ser uma arena de disputas, com estruturas fechadas e de acesso dificultado às mulheres optou-se por explorar o Poder Legislativo no que concerne a permeabilidade feminina na ocupação de cargos eletivos.

Com o conhecimento de que havia um instrumento legal aprovado com o objetivo de interferir neste cenário - a Lei n. 9.100/1995, desenvolveu-se três questões norteadoras, sendo elas: (1) de que modo se manifesta a política de cotas para as mulheres no Legislativo? (2) qual a interferência dessa política no quadro de sub-representação feminina? (3) quais fatores explicam os resultados observados acerca dessa política?

Buscou-se, então, explorar o quadro de representação das mulheres no Legislativo, a partir do estudo de caso da Câmara Municipal de Uberlândia, segundo maior colégio eleitoral do estado de Minas Gerais, apontando a sub-representação feminina como hipótese. E, a partir daí, pôr em evidência fatores que explicam esta sub-representação e quais outros explicam a insuficiência da política de cotas, uma vez que os resultados demonstravam que a medida não havia surtido efeito para modificar este quadro.

Para atender a este objetivo, estabeleceu-se uma comparação entre o cenário anterior e posterior a aprovação da ação afirmativa. No momento de início da pesquisa, em 2009, estabeleceuse o recorte temporal entre 1988 a 2008 - abordando dois processos eleitorais anteriores à aprovação da medida e seis processos posteriores. Neste texto, os dados de eleições posteriores a esse período, correspondentes a 2012 e 2016, foram acrescidos.

É importante destacar as dificuldades enfrentadas no momento da pesquisa. Dentre elas o 
Os limites da política de cotas para as disputas eleitorais: A sub-representação feminina a partir do estudo de caso da Câmara Municipal da cidade de Uberlândia Alecilda Aparecida Alves Oliveira

difícil acesso às fontes das quais foram extraídas as informações para construção do banco de dados. No site da Câmara Municipal, a maior parte das informações disponíveis eram referentes aos processos eleitorais mais recentes. Para os anteriores foi necessário contatar o Tribunal Regional Eleitoral do Estado de Minas Gerais (TRE/MG) e também buscar informações no Tribunal Superior Eleitoral (TSE).

Observou-se uma oscilação nas informações relativas ao número de registro de candidaturas, impactando, consequentemente, em outras informações relevantes. Outro fator prejudicial à época foi o fato de que os dados obtidos juntos ao TSE e TRE-MG não forneciam elementos necessários a respeito das coligações realizadas para os pleitos. Em decorrência disso, o processo de análise acerca do cumprimento da lei no município ficou comprometido.

Os dados referentes aos cargos de vereadores(as) da Câmara Municipal de Uberlândia levados em consideração foram: os Partidos que disputaram o pleito, a relação de candidatos por sexo e a quantidade de eleitos por sexo. É importante salientar que nem todos os dados disponibilizados pelo TSE e TRE-MG trazem informações agregadas por sexo, o que dificulta a análise dos dados, trazendo agravantes para uma análise que pretende observar o desempenho da lei de cotas. É importante reconhecer que, além das informações relacionadas a sexo/gênero, seria também importante informações acerca da raça/etnia, idade etc.

A seguir construiu-se um panorama dos seis últimos processos eleitorais, no que se refere a participação de homens e mulheres: 


\section{Panorama das candidaturas à Câmara Municipal de Uberlândia (1988-2016)}

\begin{tabular}{|c|c|c|c|c|c|c|}
\hline & $\begin{array}{l}\text { Candidaturas } \\
\circ-\%\end{array}$ & $\begin{array}{l}\text { Candidatur } \\
\text { as } \widehat{\sigma}-\%\end{array}$ & Total - \% & Eleitas - \% & Eleitos - \% & Total - \% \\
\hline 1988 & $46(11,91)$ & $340(89,09)$ & $386(100)$ & $03(15,78)$ & $16(84,22)$ & $19(100)$ \\
\hline 1992 & $65(13,56)$ & $414(86,44)$ & $479(100)$ & $01(04,76)$ & $20(95,23)$ & $21(100)$ \\
\hline $1996^{1}$ & $50(18,11)$ & $226(81,89)$ & $276(100)$ & $02(09,52)$ & $19(90,47)$ & $21(100)$ \\
\hline $2000^{2}$ & $57(17,37)$ & $271(82,63)$ & $328(100)$ & $02(09,52)$ & $19(90,47)$ & $21(100)$ \\
\hline 2004 & $107(25,65)$ & $310(74,35)$ & $417(100)$ & $01(04,76)$ & $20(95,23)$ & $21(100)$ \\
\hline $2008^{3}$ & $80(23,46)$ & $261(76,54)$ & $341(100)$ & $02(09,52)$ & $19(90,47)$ & $21(100)$ \\
\hline 2012 & $201(31,60)$ & $435(68,39)$ & $636(100)$ & $04(14,81)$ & $23(85,18)$ & 27 (100) \\
\hline $2016^{4}$ & $273(37,66)$ & $452(69,53)$ & $686(100)$ & $04(14,81)$ & $23(85,18)$ & 27 (100) \\
\hline
\end{tabular}

Fonte: Tribunal Superior eleitoral (TSE) e Tribunal Regional de Minas Gerais (TER-MG)

11996 - Vigência da lei de cotas para mulheres, prevendo que 20\% das vagas para candidaturas para o legislativo fossem reservadas para as mulheres;

22000 - O número de candidaturas a serem reservadas passou de 20 para $30 \%$, pois a lei sofreu alterações em 1997;

${ }^{3} 2008$ - Uma das eleitas deixou a Câmara de Uberlândia em 2010 quando eleita Deputada Estadual. Seu nome foi substituído por um suplente do sexo masculino.

${ }^{4} 2016$ - Em 2019 o Legislativo municipal foi alvo por duas operações, “Guardião” e "Má Impressão", coordenadas pelo Grupo de Atuação Especial de Repressão ao Crime Organizado (Gaeco). Neste processo, três vereadoras deixaram seus mandatos. Com a recomposição, foi mantido o número de vereadoras ainda que por coligações diferentes.

Os dados correspondentes às eleições ocorridas nos anos de 1988 e 1992 são fundamentais para a análise, uma vez que correram antes da implementação da lei de cotas. A partir deles é possível estabelecer uma comparação com os pleitos posteriores.

Em 1988, a disputa eleitoral para Câmara Municipal de Uberlândia contava com 19 (dezenove) cadeiras. Pela pesquisa, observou-se que as vagas foram disputadas por 13 (treze) partidos que lançaram 386 (trezentos e oitenta e seis) candidatos(as), numa relação de 20,315 candidatos por vaga. Destas 386 candidaturas, 46 (quarenta e seis) eram femininas, totalizando um percentual de 11,91 de candidaturas femininas em relação ao total de candidaturas. Destas 46 
Os limites da política de cotas para as disputas eleitorais: A sub-representação feminina a partir do estudo de caso da Câmara Municipal da cidade de Uberlândia Alecilda Aparecida Alves Oliveira

(quarenta e seis) candidatas, apenas 3 (três) foram eleitas, perfazendo um percentual de 15,78 em relação ao total de eleitos(as). Durante a pesquisa, verificou-se que apenas 01 (um) partido político não apresentou nenhuma candidatura feminina. As três candidatas eleitas eram oriundas de partidos distintos.

Nas eleições municipais ocorridas no ano de 1992, último processo eleitoral anterior a lei de cotas, houve um aumento de 02 (duas) cadeiras para o legislativo municipal de Uberlândia. Participaram desse processo 15 (quinze) partidos políticos, com um total de 479 (quatrocentos e setenta e nove) candidaturas. A relação de candidatos(as) por vaga foi de 22,809 . Deste total de candidaturas, 65 (sessenta e cinco) foram de mulheres, alcançando um percentual de 13,569 em relação ao total de candidaturas. Já o número de eleitas caiu de 03 (três) para 01 (um) com relação à eleição anterior. Merece destaque o fato de que essa mulher foi eleita com o maior número de votos, uma votação expressiva para a disputa. Do mesmo modo que na eleição de 1988, um partido político deixou de apresentar candidaturas feminina.

Em uma comparação aos dois pleitos eleitorais, identifica-se que não aconteceram avanços significativos em relação ao número de candidaturas femininas. $O$ aumento no percentual de candidaturas femininas foi apenas de pouco mais 1,6\%, mantendo-se um equilíbrio com relação ao número de homens candidatos. E com relação ao número de eleitos, é possível identificar uma regressão no número de eleitas, caindo de 3 em 1988 para 1 em 1992.

As eleições realizadas no ano de 1996 contaram com o diferencial: a vigência da lei de cotas para mulheres, prevendo que $20 \%$ das vagas para candidaturas para o legislativo fossem reservadas para as mulheres. Neste ano, a disputa para o legislativo uberlandense foi feita por 15 (quinze) partidos políticos, registrando um total de 276 (duzentas e setenta e seis) candidaturas. O número de candidaturas em 1996 caiu pela metade em comparação às eleições de 1992. Com isso, a relação de candidatos(as) por vaga foi de 13,143.

No que se refere às candidaturas de mulheres, do total de 276 (duzentas e setenta e seis) foram registradas 50 (cinquenta) candidaturas femininas e, como nas eleições anteriores, 01 (um) dos 15 partidos registrou apenas candidaturas masculinas. Em observação ao número de eleitos(as), nota-se que o número de mulheres continuou baixíssimo. Das 21 cadeiras, apenas 2 foram ocupadas por mulheres.

Quando se analisa o resultado da política de cotas por sexo no legislativo municipal, é possível constatar a dificuldade para apresentação de candidaturas femininas. Nas eleições de 1996 muitos partidos alegaram terem sido pegos de surpresa, pois os intervalos entre a discussão, a aprovação da lei e sua implementação foram muito curtos. Com isso, o período previsto entre a 
Os limites da política de cotas para as disputas eleitorais: A sub-representação feminina a partir do estudo de caso da Câmara Municipal da cidade de Uberlândia Alecilda Aparecida Alves Oliveira

aprovação da legislação eleitoral e o encerramento do prazo de filiação partidária (condição indispensável para se pleitear uma candidatura) foi de apenas 45 dias (MALHEIROS, 2000).

Partindo para a análise das eleições realizadas no ano 2000, segunda eleição municipal após da aprovação da política de cotas por sexo, vemos que o cenário não sofreu alterações no que diz respeito ao objeto de pesquisa aqui proposto. Cabe destacar que, para as eleições de 2000, o número de candidaturas a serem reservadas passou de 20 para 30\%, pois a lei sofreu alterações em 1997.

O número de partidos na disputa se manteve nas eleições de 2000 (15 partidos políticos), registrando o total de 328 (trezentos e vinte e oito) candidaturas, das quais apenas 57 (cinquenta e sete) eram de mulheres. Esses números indicam que apenas $17,37 \%$ das candidaturas eram femininas, mantendo o baixo registro de candidaturas de mulheres. Observando o número de eleitas, manteve-se apenas 02 (duas) mulheres em um total de 21 cadeiras. Dois partidos políticos deixaram de apresentar candidaturas de mulheres nas eleições ocorridas neste ano, infringindo a lei de cotas estabelecida.

As eleições de 2004, por sua vez, apresentaram algumas mudanças no quadro da disputa legislativa. A primeira delas, que merece atenção, está relacionada ao número de partidos presentes na disputa eleitoral. Durante os pleitos anteriores observou-se que havia uma estabilidade no número de partidos que disputavam o processo eleitoral. Nestas eleições, em especial, o número que antes era em média de 15 partidos, passou para 25. Identifica-se, então, uma presença grande de partidos pequenos e novos no cenário político municipal.

O número total de candidaturas, em 2004, foi de 417 (quatrocentas e dezessete), das quais 107 (cento e sete) eram de mulheres. Com essa alteração no número de partidos disputando o processo, alterou também o número de candidaturas femininas, perfazendo 25,65\% do total de candidaturas. O aumento no número de candidaturas não significou, entretanto, um aumento no número de mulheres eleitas - apenas 01 (uma) mulher foi eleita vereadora no ano de 2004. Dos 25 partidos, 01 deixou de registrar candidatas mulheres.

No ano de 2008 observou-se, mais uma vez, que o cenário não sofreu alterações significativas em comparação às eleições anteriores. O número de partidos disputando o processo caiu de 25 (vinte e cinco) para 23 (vinte e três) e o número de candidaturas registradas caiu para 341 (trezentas e quarenta e uma), numa relação de 16,2 candidatos(as) por vaga. Dos 23 (vinte e três) partidos presentes na disputa, 07 (sete) não registraram candidatura feminina.

O número de candidaturas de mulheres registradas foi 80 (oitenta), perfazendo 23,46\% do total de candidaturas. Neste ano, 02 (duas) mulheres foram eleitas vereadoras, sendo importante mencionar que uma delas deixou a Câmara de Uberlândia em 2010 quando foi eleita Deputada 
Os limites da política de cotas para as disputas eleitorais: A sub-representação feminina a partir do estudo de caso da Câmara Municipal da cidade de Uberlândia Alecilda Aparecida Alves Oliveira

Estadual. Seu nome foi substituído por um suplente do sexo masculino. Merece destaque o fato de que essa mesma candidata conseguiu a façanha de ser a vereadora mais votada por duas vezes na história da cidade. Na primeira votação foi eleita com mais de 12 (doze mil) votos e na última, recebeu quase 10 (dez) mil votos. Foi a segunda mais votada na ocasião.

Com o objetivo de produzir um acúmulo sobre a temática, pôde-se acrescentar informações referentes ao cenário eleitoral no que compete aos anos de 2012 e 2016. Em 2012 apenas 201 (duzentas e uma) candidaturas, de um total de 636 (seiscentas e trinta e seis) foram femininas, perfazendo 31,6\%. Neste processo eleitoral, a Câmara de Uberlândia já contava 27 (vinte e sete) cadeiras, o número atual. Destas, apenas 04 (quatro) foram ocupadas por mulheres, perfazendo o total de $14,81 \%$.

No ano de 2016, foram registradas 273 (duzentas e setenta e três), candidaturas femininas dentro de um total de 686 (seiscentas e oitenta e seis) candidaturas. Com isto, atingiu-se o percentual de 37,66\% de candidaturas femininas. Deste total, manteve-se o número de eleitas no pleito anterior, apenas 04 (quatro). Destaca-se o fato de que uma das mulheres eleitas era transexual, o que é interessante do ponto de vista da diversidade.

Em 2019, penúltimo ano de mandato, o Legislativo uberlandense foi alvo de duas investigações do Ministério Público Estadual (MPE), coordenadas pelo Grupo de Atuação Especial de Repressão ao Crime Organizado (Gaeco). Denominadas como “Guardião" e "Má Impressão", os(as) envolvidos(as) foram denunciados por crimes relacionados ao desvio de recursos públicos da Câmara Municipal de Uberlândia. Entre os(as) denunciados(as) estavam empresários do setor gráfico da cidade e vereadores, sendo a maioria presos por uso irregular de dinheiro público.

No que concerne ao objeto de estudo proposto nos interessa o fato de que, neste processo, vereadoras também estão envolvidas nas investigações e, caso deixem seus mandatos, poderemos ter uma reconfiguração do parlamento municipal, alterando o número de vereadoras. Para exemplificar, já se desenrolou a primeira renúncia ao cargo por parte de uma parlamentar, filiada ao Partido Democrático Trabalhista (PDT), após firmar acordo com o Ministério Público de Minas Gerais (MPMG) no final de 2019. Sua investigação decorria da acusação de desvios de verbas de gabinete em serviços de impressão gráfica na cidade de Uberlândia ${ }^{5}$.

No que concerne a pesquisa, torna-se importante enfatizar que os números obtidos junto ao TSE e TRE-MG não nos forneciam os elementos para saber quais foram as coligações e quais

\footnotetext{
${ }^{5}$ Disponível em: https://diariodeuberlandia.com.br/noticia/23800/vereadora-flavia-carvalho-renuncia-aposser-presa-na-operacao-ma-impressao.
} 
Os limites da política de cotas para as disputas eleitorais: A sub-representação feminina a partir do estudo de caso da Câmara Municipal da cidade de Uberlândia Alecilda Aparecida Alves Oliveira

partidos lançaram chapas próprias e, por isso, não podemos aferir quantas candidaturas de homens e mulheres cada partido/coligação registrou. Mas, de um modo geral, os números obtidos não deixam dúvida com relação ao baixo número de candidaturas femininas comparadas com o número de candidaturas masculinas. As candidaturas femininas num quadro geral, não atingem nem mesmo 1/3 do total de candidaturas e os reflexos com relação ao número de eleitas são ainda piores: a média de eleitas para a Câmara Municipal tende a ser de apenas duas mulheres num total de 21 cadeiras.

Outro agravante é que, numa observação mais atenta com relação aos números de eleitos e eleitas, é possível identificar que a Câmara Municipal de Uberlândia, como muitas outras espalhadas pelo Brasil, não passa por um processo do que poderíamos chamar de "oxigenação". O que se quer dizer com isso é que as cadeiras da Casa são sempre ocupadas pelos mesmos partidos e, muitas vezes, pelos mesmos representantes que estão lá há vários mandatos.

\section{Considerações Finais}

Em busca de um aprofundamento da discussão sobre a representação feminina nos espaços de tomada de decisão da cidade, pôde-se realizar um estudo acerca do desempenho da lei de cotas por sexo para a disputa legislativa. Os dados coletados e trabalhados corroboram com a hipótese apresentada de que há uma baixa participação das mulheres na política institucional, assim como já havia sido constatado por outros(as) pesquisadores. Levando-se em consideração que se trata de um estudo de caso, pode-se afirmar que a representatividade feminina na Câmara Municipal de Uberlândia é reflexo do que acontece em outros colégios eleitorais brasileiros e, em alguns casos, em outras partes do mundo. E, como apresentado, também em outras instâncias do Legislativo.

É fato que a política de cotas aprovada pelo Congresso Nacional significou um avanço importante no que diz respeito à participação política de mulheres. Essa iniciativa deu abertura para que o problema da ausência de mulheres nos espaços institucionais entrasse para a agenda do debate público. E este fenômeno, mesmo passado mais de duas décadas, ainda se faz presente, o que nos leva a entender que ação afirmativa apresenta várias limitações que estão ligadas a uma confluência de fatores.

Analisando-se os processos eleitorais, é possível ver que vários aspectos vinculados à estrutura política, perpassando o sistema eleitoral, contextos culturais e socioeconômicos, são responsáveis pelo entrave à participação política feminina no Brasil. Durante a pesquisa identificouse alguns elementos relevantes para a compreensão. 
Os limites da política de cotas para as disputas eleitorais: A sub-representação feminina a partir do estudo de caso da Câmara Municipal da cidade de Uberlândia Alecilda Aparecida Alves Oliveira

No caso do baixo número de candidaturas e, com isso, do descumprimento da lei de cotas, algumas explicações são dadas mais correntemente. Dentre elas, temos partidos políticos, por um lado, que alegam que não há mulheres dispostas a se candidatar, pois elas não se interessam por política. Deste modo, acabam responsabilizando as mulheres e transferindo o problema para uma esfera individual, tratando a questão como apatia e não como um problema do nosso modelo de democracia. As mulheres, por outro lado, alegam que a política é um espaço ainda de difícil inserção. Os próprios partidos políticos são vistos como entidades de resistência à participação das minorias sociais em geral.

Há ainda o fato de que muitos partidos atuam no cenário político brasileiro apenas como legendas, não exercendo uma atuação orgânica. Com isto, a tarefa de discutir e estimular a participação das mulheres aparece somente no momento de formação de chapa para disputa no processo eleitoral e servindo apenas a interesses pessoais transitórios de algumas lideranças partidárias. É recorrente, neste tipo de agremiação partidária, a utilização de nomes de mulheres como "laranjas", ou seja, apenas para completar a chapa e/ou garantir o cumprimento da lei.

Outra alegação que comumente aparece entre as mulheres é a dificuldade que elas têm em conseguir apoio financeiro para seguir adiante com uma candidatura. Os partidos políticos muitas vezes não oferecem as mesmas condições para todos os candidatos que estão na disputa eleitoral. $\mathrm{E}$ as maiores prejudicadas com isso, consequentemente, são as mulheres. Com a falta de apoio financeiro e recursos materiais para as campanhas, as mulheres são colocadas em situação de desvantagem em relação aos homens.

Outra explicação observada está nas dificuldades que as mulheres encontram para administrar as tarefas que exercem e conciliá-las com a atuação na arena política. O papel exercido por elas na esfera familiar, os cuidados com a casa, com os(as) filhos(as), o trabalho doméstico e a atuação no mercado de trabalho acabam sendo empecilhos para a participação feminina. Esta dicotomia entre público e privado parece ser o ponto central nesse debate. Poderia a situação ainda ser explicada pela lógica da reprodução social, em que há uma divisão sexual do trabalho desigual entre homens e mulheres sendo tratada como “natural". É necessário, neste sentido, alterar a lógica que responsabiliza a mulher no exercício de diversas funções fazendo com que essas responsabilidades sejam compartilhadas.

No que concerne a legislação, especificamente, está o fato de que a política cotas se trata de uma medida que assegura apenas as candidaturas na disputa eleitoral e não as cadeiras no espaço institucional. A participação no processo eleitoral não garante a elegibilidade de mulheres; é 
Os limites da política de cotas para as disputas eleitorais: A sub-representação feminina a partir do estudo de caso da Câmara Municipal da cidade de Uberlândia Alecilda Aparecida Alves Oliveira

necessário que se garantam, minimamente, condições para que mulheres e homens participem com as mesmas condições do processo eleitoral.

Desde que foi aprovada, os partidos políticos vêm mostrando dificuldade no seu cumprimento. No momento de implantação, o Tribunal Superior Eleitoral (TSE) tomou a decisão de não firmar entendimento em relação ao descumprimento da lei, delegando aos Tribunais Regionais Eleitorais (TRE). Dessa forma, nos estados onde houve uma atuação mais firme dos tribunais no sentido de se fazer cumprir a lei, obtiveram-se os melhores índices.

No ano de 2009 a Lei 12.034 alterou a redação da lei anterior de “deverá reservar" para "preencherá", tornando obrigatório o cumprimento do dispositivo legal e punindo os partidos descumpridores com a impugnação da chapa. Juntamente com essa alteração, foram aprovadas duas outras medidas com o intuito de promover e fortalecer a participação política feminina e incentivar suas candidaturas: a destinação de dez por cento $(10 \%)$ do tempo de propaganda partidária e de cinco por cento $(5 \%)$ dos recursos do fundo partidário para a formação política e o incentivo à participação feminina. Nos últimos pleitos têm se observado que Tribunal Superior Eleitoral (TSE) tem sido mais incisivo no acompanhamento.

Mas este cenário nos abre possibilidade para discutir o nosso modelo de representação política, já indicado por muitas pesquisas como um fator influente sobre as chances de acesso das mulheres a esses espaços.

No Brasil, vigora o sistema proporcional. Este modelo pode adotar técnicas diferentes na estruturação das candidaturas pelos partidos e no modo como os eleitores escolhem seus candidatos, como o voto de legenda e o escrutínio de lista. No voto de legenda, o(a) eleitor(a) define seu voto a uma legenda partidária, ou seja, seu voto não é dado a um candidato ou uma lista pré-ordenada de candidatos e sim ao partido político.

No que diz respeito ao escrutínio de listas, pode-se dizer que existem basicamente três tipos: o primeiro tipo é a lista fechada, na qual os partidos estabelecem a hierarquia de prioridades dos seus candidatos e os eleitores votam na lista partidária como um todo, sem poder alterar a sua ordem, ou seja, vota-se predominantemente no partido. O segundo tipo é o escrutínio de lista semifechada ou flexível, na qual é apresentada uma ordem de prioridades pelos partidos, mas isto pode vir a ser alterado pelos eleitores no momento de votação e com isso redefinir a prioridade dos nomes. E o terceiro tipo é o escrutínio de lista aberta, em que o partido apresenta um universo de nomes, sem ordem de prioridade formal, e o eleitor dá seu voto num candidato específico.

No caso brasileiro, o(a) eleitor(a) tem a possibilidade de exercer dois tipos de votação: o voto no candidato, através do escrutínio de lista aberta, e o voto na legenda partidária. O escrutínio 
Os limites da política de cotas para as disputas eleitorais: A sub-representação feminina a partir do estudo de caso da Câmara Municipal da cidade de Uberlândia Alecilda Aparecida Alves Oliveira

de lista aberta é um aspecto bastante debatido quando se trata da elegibilidade feminina, sendo apontado como um dos fatores responsáveis pela baixa representatividade das mulheres.

Um dos apontamentos é a característica extremamente individualizada que a competição eleitoral agrega nesse modelo, acentuando o peso da influência e articulações individuais em detrimento da influência exercida pela agremiação partidária ou, ainda, do projeto eleitoral apresentado pela organização partidária.

Uma das perspectivas é de que listas fechadas ou semifechadas tendem a ser mais favoráveis à elegibilidade de mulheres quando comparadas à lista aberta. Entretanto, é importante ponderar o fato de que na lista fechada a ordem dos nomes pode não ser necessariamente favorável às mulheres, uma vez que são definidas a partir de avaliações das direções partidárias. Em busca de solucionar este problema, uma possibilidade poderia ser a lista pré-ordenada com alternação entre os sexos/gênero.

Por fim, no que concerne ao debate acerca da presença feminina em espaços institucionais, torna-se importante a problematização - que poderá ser trabalhada em um texto futuro - acerca da diversidade na representatividade. Nos importa a representatividade feminina? Sim, mas é importante entender que a representatividade não fala por si só. Necessitamos compreender o perfil das(os) eleitas(as) e o projeto político para o qual atuam em defesa, uma vez que muitos deles podem caminhar contra os interesses de outras mulheres e, especialmente, da classe trabalhadora.

\section{Referências}

BIROLI, Flávia. O público e o Privado. In.: MIGUEL, Luis Felipe; BIROLI, Flávia. Feminismo e política: uma introdução. São Paulo: Boitempo, 2014, p. 31-46.

DIÁRIO DE UBERLÂNDIA. Vereadora Flávia Carvalho renuncia após ser presa na operação Má Impressão. Uberlândia. 16 de deze de 2019. Disponível em: $<\underline{\text { https://diariodeuberlandia.com.br/noticia/23800/vereadora-flavia-carvalho-renuncia-apos-ser- }}$ presa-na-operacao-ma-impressao >. Acesso em 17 de dez. de 2019.

GROSSI, Miriam Pillar; MIGUEL, Sônia Malheiros. Transformando a diferença: as mulheres na política. Revista Estudos Feministas, Florianópolis, v. 9, n. 1, p. 167, jan. 2001. ISSN 1806-9584. Disponível em: < $\quad$ https://periodicos.ufsc.br/index.php/ref/article/view/S0104-

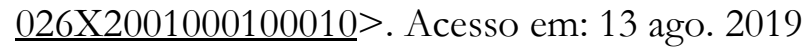

MARIANO, Silvana Aparecida \& SOUSA, Márcio Ferreira de. Autonomia feminina e concepções de direito entre mulheres beneficiárias do Programa Bolsa Família. Revista Em Pauta: teoria social e realidade contemporânea, n. 44, v. 17, p. 165 - 180, 2019.

MIGUEL, Sônia Malheiros. A política de cotas por sexo: um estudo das primeiras experiências no 
Os limites da política de cotas para as disputas eleitorais: A sub-representação feminina a partir do estudo de caso da Câmara Municipal da cidade de Uberlândia Alecilda Aparecida Alves Oliveira

Legislativo brasileiro. Brasília: CFEMEA, 2000.

OKIN, Susan Moller. Gênero, o público e o privado. Rev. Estud. Fem., Florianópolis, v. 16, n. 2, pág. 305-332, agosto de 2008. Disponível em $<$ http://www.scielo.br/scielo.php?script=sci_arttext\&pid=S0104-

026X2008000200002\&lng=en\&nrm=iso $>$. acesso em 13 de agosto de 2020.

RANGEL, Patrícia. Nova lei eleitoral = nova vida para as mulheres na democracia representativa? In. Jornal fêmea, no 164. Brasília: CFEMEA, 2010.

TRIBUNAL SUPERIOR ELEITORAL. Número de mulheres eleitas em 2018 cresce 52,6\% em relação a 2014. Disponível em: http://www.tse.jus.br/imprensa/noticiastse/2019/Marco/numero-de-mulheres-eleitas-em-2018-cresce-52-6-em-relacao-a-2014. Acesso em 25 de agosto de 2019.

TRIBUNAL SUPERIOR ELEITORAL. Mulheres representam 52\% do eleitorado brasileiro. Disponível em: http://www.tse.jus.br/imprensa/noticias-tse/2018/Marco/mulheresrepresentam-52-do-eleitorado-brasileiro. Acesso em 15 de setembro de 2019. 